\title{
O Caso Aunós na versão da grande imprensa carioca e do Itamaraty
}

\author{
SANDRA M. L. BRANCATO*
}

\begin{abstract}
Resumo: O artigo examina, através da imprensa e da correspondência diplomática, as implicações que trouxe a nomeação de Eduardo Aunós para ocupar a Embaixada da Espanha, no Rio de Janeiro, em janeiro de 1946. A extensa rede de problemas suscitados entrelaça interesses dos governos brasileiro, argentino, norte-americano, espanhol e alemão, em dois momentos distintos: 1942 e 1946.
\end{abstract}

\begin{abstract}
The following article examines, by means of press and diplomatic correspondence, implications related to the nomination of Eduardo Aunós as ambassador of the Spanish Embassy in Rio de Janeiro in January of 1946. An extended net of subsequent problems, connects the interests of the Brazilian, Argentine, NorthAmerican, Spanish and German governments in two diverse moments: 1942 and 1946.
\end{abstract}

Palavras-chave: Imprensa e História. Política externa brasileira. Relações internacionais.

Key words: Press and History. Brazilian foreign policy. International relations.

A questão político-diplomática denominada de Caso Aunós aqui analisada, que interliga interesses dos governos brasileiro, argentino, espanhol, norte-americano e alemão, põe à tona uma série de situações conflitantes ligadas à II Guerra Mundial, mesmo em 1946, quando esse conflito já havia terminado.

A documentação diplomática que será examinada, além de revelar a posição oficial do governo brasileiro sobre o intrincado Caso Aunós, possibilitará também abrir perspectivas mais amplas para o entendimento das matérias de alguns dos principais jornais da grande imprensa carioca - Diário de Notícias, O Jornal, Diário Carioca, Jornal do Brasil, Jornal do Comércio e Correio da Manhã ${ }^{1}-$ que se ocuparam em opinar sobre o referido Caso.

Professora no Programa de Pós-Graduação em História da Pontifícia Universidade Católica do Rio Grande do Sul. E-mail: brancato@pucrs.br

1 As informações relativas a cada um desses jornais, sua linha política e proprietários foram recolhidas basicamente em Dicionário Histórico-Biográfico Brasileiro Pós-1930.

Estudos Ibero-Americanos. PUCRS, v. XXXIII, n. 2, p. 134-155, dezembro 2007 
Antes, no entanto, de iniciar especificamente a análise do Caso Aunós, a partir das fontes indicadas, é preciso que sejam colocados os fatos geradores do mesmo.

\section{O Caso Aunós: questões preliminares}

Eduardo Aunós, o pivô do Caso que leva seu nome, em 1942, quando aconteceram as primeiras questões que o envolveriam, já tinha um currículo respeitável como político, diplomata e intelectual. ${ }^{2}$ Estaria, assim, habilitado a chefiar a missão que, em 12 de abril de 1942, partiu de Cádiz, na Espanha, com destino a Buenos Aires, para negociar com o governo argentino um tratado comercial de alto interesse mútuo, considerando as limitações impostas aos dois países pelos desdobramentos da Segunda Guerra Mundial. ${ }^{3}$

Rio de Janeiro: Fundação Getúlio Vargas, Centro de Pesquisa e Documentação de História Contemporânea do Brasil (CD-ROM).

2 Em 15 de janeiro de 1946, Mário de Pimentel Brandão, embaixador brasileiro em Madri, escrevia para Leão Velloso, Ministro das Relações Exteriores do Brasil, um ofício onde informava que Aunós, nomeado para a embaixada espanhola no Brasil, em janeiro de 1946, já tinha ocupado vários cargos. Fora deputado, Subsecretário do Ministério do Trabalho, Embaixador da Espanha na Bélgica e Ministro da Justiça de Francisco Franco; era autor de múltiplas leis, como também realizações sociais; publicara livros sobre legislação trabalhista considerados verdadeiros clássicos e colaborara, como redator, na Enciclopédia Hispânica; pertencia à Academia de Ciências Morais e Políticas; destacava-se igualmente como advogado, jornalista, literato e historiador. Pimentel Brandão ainda acrescentava: "sua nomeação é sem dúvida, uma prova de alta consideração ao nosso país, onde até hoje a Espanha jamais teve um representante de tão elevada estatura moral, intelectual e política" (cf. Arquivo Histórico do Itamaraty [AHI], Madrid - Ofícios - Jan.1946-30/3/1). Chama a atenção também que, após ter sido nomeado Embaixador para o Brasil, em fevereiro de 1946, foi oferecido em Madri um banquete para homenageá-lo, onde compareceram mais de quatrocentas pessoas, entre elas autoridades de destaque como: Alfaro vicepresidente das Cortes e o prefeito de Madri, Alcocer. Uma homenagem com tais características é mais uma evidência do prestígio de Aunós na sociedade e na política espanhola (cf. jornal $A B C$, "El banquete al Embajador español en el Brasil", Madri, 3 de fevereiro de 1946, p. 38).

3 A Argentina, desde a Reunião de Consultas dos Ministros de Relações Exteriores do Continente, realizada entre 15 e 28 de janeiro de 1942, estava em uma situação difícil, pois junto com o Chile, optou por permanecer neutra ante o conflito mundial, ao contrário da esmagadora maioria das repúblicas americanas. Tal neutralidade custou ao governo sofrer uma série de embargos por parte dos EUA e uma série de pressões para que reprimisse a ação do Eixo na Argentina. No que se refere à Espanha, enfrentava uma situação bastante complicada, dado o bloqueio diplomático que sofria o governo de Franco por parte de vários países europeus e americanos. Esse mesmo governo enfrentava, ainda, acusações por apoiar ações da Alemanha de Hitler. 
Após a chegada em Buenos Aires, em 19 de maio de 1942, iniciaram as negociações com a equipe de Aunós e os ministros argentinos que negociariam o tratado: Ruiz Guiñanzú, das Relações Exteriores, Alvarado, da Fazenda, e Amadeo y Videla, da Agricultura. Beatriz J. Figallo, que estudou detidamente as relações Argentina/Espanha entre 1942 e 1952, afirma que Aunós esteve distante das reuniões que davam forma ao tratado, ficando Blas Huete à frente da delegação espanhola. A autora acrescenta que Aunós

Se ocupó en una intensa actividad de tipo cultural y político, que provocó la reacción de órganos e prensa liberales e incluso cierta tención en las mismas tratativas del acuerdo, al incurrir Aunós en abiertas críticas a las instituciones de la democracia, en la apología del totalitarismo como forma de gobierno y de un hispanismo triunfante e expansivo, temas que desarrolló ampliamente en conferencias, transmisiones radiales y agasajos, como por ejemplo el brindado por los directivos de los Legionarios Civiles de Franco en Buenos Aires. ${ }^{4}$

O tratado, finalmente assinado em 5 de setembro de 1942, estabelecia, ainda segundo Figallo,

la venta a crédito al gobierno español de un millón de toneladas de trigo y 3.500 de tabaco, en el plazo máximo de 18 meses, comprometiéndose España a enviar a cambio a la Argentina 30.000 toneladas de hierro y acero anuales, a razón de 7.500 por trimestre, y a construirle dos barcos mercantes de 9.000 toneladas y un destructor del tipo Cervantes, en un plazo de 30 meses, y también en facilitar medios de transporte de petróleo. En cuanto al trigo, la entrega se haría sobre vagón-puerto por cupos trimestrales mínimos de 120.00 toneladas de la cosecha 1941-1942. ${ }^{5}$

O tratado contemplava um anexo confidencial, classificado com o número 7 , conforme consta de documento que se encontra no Arquivo do Ministério de Assuntos Exteriores de Madri, que previa a venda de outros produtos espanhóis para a Argentina: metais e derivados, cabos de aço, metais ferrosos, soldas, ferramentas, combustíveis, pólvora, explosivos, motores de avião, páraquedas, bombas de demolição e incendiárias, metralhadoras e canhões para aviões. ${ }^{6}$

A compra dos itens citados no anexo deveria ser encaminhada para os seguintes órgãos argentinos: Servicio Hidrográfico, Cons-

4 El Protocolo Perón-Franco: relaciones hispano-argentinas, 1942-1952. Buenos Aires: Ediciones Corregidor, 1992, p. 23.

5 Cf. ibidem.

6 Cf. ibidem. 
trucciones Navales, Dirección de Aviación Naval e Dirección General de Fabricaciones Militares. Tal relação de compras era problemática, na medida em que previa a aquisição de equipamento militar pela Argentina, então afastada de um comprometimento maior com os Estados americanos envolvidos na guerra.

Como elemento agravante, houve denúncias de que o general Domingo Martínez, chefe da polícia de Buenos Aires, entrara em contato com Aunós e o Encarregado de Negócios da Alemanha em Buenos Aires, Enrich Otto Meynen, para propor um comércio triangular que se faria da seguinte maneira, conforme aparece especificado no jornal $A B C$ :

Según un informe del embajador Meynen fue concertado un acuerdo secreto hispano-argentino para suministrar municiones a la $\mathrm{Ar}-$ gentina [...] que "al incluir a España en las negociaciones comerciales se facilitaría un tratado triple con España" por el cual España entregaría armas a la Argentina, que serian repuestas en España por otras alemanas; España entregaría a la Alemania materias primas, que a su vez serian reemplazadas en España por la Argentina. Entre estas materias primas figurarían lana, caseína, aceite de linaza y cueros. Las carnes y el sebo serian enviadas para la Argentina para su reexportación a Alemania. ${ }^{7}$

Existem alguns documentos que confirmam a existência de tratativas para oficializar a intermediação de acordos entre os países mencionados. Meynen, por exemplo, em 16 de agosto de 1942, escreveu para Berlim, afirmando que "hay acuerdos secretos relacionados con las entregas españolas de armamentos, especialmente pólvora [...] que pueden cumplirse solo con apoyo alemán". 8 Também no relato de interrogatório feito ao Agregado Naval da Alemanha em Buenos Aires, capitão Dietrich Niebuhr, pelo Departamento de Estado norte-americano, consta que:

En agosto de 1942, Niebuhr fue llamado al Ministerio Argentino de Marina y consultado sobre la posibilidad de la entrega por parte de Alemania, a través de canales españoles, de un embarque de material bélico. Esto iba a realizarse a través de la intermediación de la misión económica AUNÓS. Se mencionaran en especial submarinos,

7 "Washington acusa Argentina - Un extensísimo documento habla de la colaboración del régimen con el Eje". Madrid, 13 de fevereiro de 1946, p. 8-9.

8 Cf. Telegrama 29292, citado por Robert A. Potash, em El ejército y la política en la Argentina (1928-1945). De Yrigoyen a Perón. Buenos Aires: Sudamericana, 1984, p. 192. 
hasta seis en total; también se deseaban aviones, armas antiaéreas, y municiones de todo tipo. ${ }^{9}$

Contudo, no mesmo relato, também consta que a negociação sobre o envio de armamentos "nunca fue mas allá de la etapa de las discusiones".

Outro fato, que igualmente pode ser relacionado às tratativas de concretizar o acordo triangular Argentina/Espanha/Alemanha, foi a Missão que Osmar Alberto Hellmuth deveria cumprir na Alemanha, no final de 1943. Essa Missão consistia em Hellmuth chegar à Alemanha através da Espanha, onde fora lotado no consulado de Barcelona, como cônsul de terceira classe. Uma vez no país germânico, deveria voltar a negociar a questão do envio de material bélico para a Argentina. A Missão resultou em um rotundo fracasso, ${ }^{10}$ mas o que interessa aqui é registrar a existência de mais uma denúncia de ligações entre Alemanha e a Argentina, com o objetivo de obter armamentos. ${ }^{11}$

Foi com base nessas supostas ligações argentinas, além de outras fora do contexto aqui abordado, que, em 12 de fevereiro de 1946, o governo dos Estados Unidos divulgou através da imprensa internacional um longo depoimento de oitenta e seis páginas, onde denunciava aos demais governos americanos a estreita ligação que a Argentina tivera com o governo nazista durante a guerra. ${ }^{12}$ Ofi-

9 Cf. RAPOPORT, Mario. ¿Aliados o Neutrales? La Argentina frente a la Segunda Guerra Mundial. Buenos Aires: Eudeba, 1988, p. 192.

10 Hellmuth, acusado de espionagem a favor da Alemanha, foi preso pelas autoridades britânicas na ilha de Trinidad, em novembro de 1943. Levado para Londres, permaneceu preso até o final da guerra, recebendo também a acusação de pretender negociar material bélico com a Alemanha para o governo argentino. No ano de 1945, voltou para a Argentina, onde, após ser detido, provou que partira para a Europa em missão conhecida pelas autoridades argentinas. Com tal argumento, conseguiu uma certa reabilitação na sociedade internacional e de seu país (sobre essa questão consultar parte da documentação pertinente em RAPOPORT, op. cit., p. 100-107).

11 As ligações entre a Argentina e a Alemanha com o objetivo de obter material bélico eram já antigas. Apenas para citar alguns exemplos, em 1936 uma comissão militar composta por generais argentinos esteve em Paris e, mais tarde, em Roma, com aquele objetivo. Em Buenos Aires, a firma Staudt \& CIA, com a participação da Krupp e da Siemens-Schuckert, fundou a Compañia de Comercio com o propósito de agilizar a compra de armas na Alemanha. A Aeroposta Argent renovou a frota de correio aéreo com aviões Junker e empregou mecânicos e instalações da Lufthansa no aeroporto de Quilmes (cf. http:/ / www.argentina-rree.com/9/9-034.htm, consultado em 23 de setembro de 2004).

12 O principal mentor do documento foi Spruille Braden, que, entre maio e outubro de 1945, fora embaixador dos EUA na Argentina. Desde essa época, movia intensa campanha contra Perón, a quem atribuía uma atuante colaboração com o Eixo. Em fevereiro, então ocupando o cargo de Ajudante do Secretário de Estado norteamericano para assuntos americanos, pretendeu com a publicação do Livro Azul 
cialmente, o documento intitulava-se Consultas entre as repúblicas americanas a respeito da situação argentina, Memorandum do governo dos Estados Unidos, mas ficou conhecido e amplamente divulgado com o nome de Livro Azul. ${ }^{13}$

É entre as denúncias reunidas no Livro Azul que o Caso Aunós começa a tomar um contorno mais definitivo, pois, segundo a publicação, o protagonismo do embaixador espanhol como intermediador das ligações Argentina/Espanha/Alemanha era um fato irrefutável. Contudo, não só as acusações sobre Aunós, como as demais contidas no Livro Azul, foram amplamente contestadas por argentinos e espanhóis. Em 1946, Perón negou a ligação de seu país com o Eixo em um longo documento, de forte conotação nacionalista, cujo título, Libro Azul y Blanco, sugestivamente, já era uma clara alusão à bandeira argentina, emblemático símbolo da nação.

No que se refere ao governo espanhol, não houve uma negação peremptória em torno de o acordo triangular para o comércio de armas entre Argentina/Espanha/Alemanha, como se evidencia em informe com termos bastante vagos encaminhado pelo Departamento de Política Económica Española ao Ministro das Relações Exteriores espanhol Martín Artajo: "hechos prácticos que patenticen una acción combinada germano-hispano-argentina a fines de reforzar la potencialidad bélica de este último país, no existe absolutamente ninguna". ${ }^{14}$ A inexistência de "hechos prácticos", podese depreender, não inviabilizava a existência, pelo menos, de negociações.

Aunós, por sua vez, negará taxativamente qualquer participação no aludido acordo triangular, mas, mesmo assim, não con-

desmobilizar os eleitores de Perón que concorria à presidência argentina, acusandoo de conluio com os nazistas. Sua estratégia resultou em um fracasso, pois os peronistas conseguiram reverter a contra-propaganda de Braden a seu favor usando o slogan: "Braden ó Perón". Tal slogan sintetizava a idéia de que havia uma evidente intervenção norte-americana na política interna argentina e que a eleição de Perón era o caminho para neutralizá-la. Em 24 de fevereiro de 1946, Perón chegava à presidência de seu país.

13 O dossiê de denúncias foi chamado de Livro Azul porque sua capa tinha essa cor. Segundo divulgou o Departamento de Estado, o conteúdo do Livro Azul estava baseado, na maior parte, em documentos alemães capturados pelos Aliados. As acusações referentes à colaboração do governo argentino com os nazistas incluíam ações subversivas que teriam sido movidas contra vários países americanos.

14 Cf. FIGALLO, op. cit., p. 63. Essa mesma autora pondera que "ni España, ni la Argentina podían lanzarse a una desmentida puntual de las acusaciones, pues el anejo número 7 era incriminatorio, como así también las misiones militares que inúltimente peregrinaron a Madrid. La cuestión quedaba entonces en el peor de los supuestos, reducida al grado de tentativa" (p. 63). 
seguiu evitar que se criasse em torno do acordo uma questão politico-diplomática, onde seria um dos principais protagonistas.

\section{Aunós e as repercussões na imprensa e no Itamaraty}

Quando, em 12 de fevereiro de 1946, as denúncias do Livro Azul tornaram-se públicas, Aunós se encontrava em viagem, a bordo do navio Cabo de Buena Esperanza, que partira de Cadiz, na Espanha e fazia escala em Willimsted (Curaçao). O destino final de Aunós era o Rio de Janeiro, onde deveria assumir a Embaixada da Espanha. Esse é justamente o ponto que liga mais de perto o Brasil com as denúncias do Livro Azul, onde, como se viu, Aunós estava incluído.

A questão então colocada era muito direta: como aceitar ter no Brasil um representante estrangeiro sobre o qual recaíam acusações tão comprometedoras? Iniciava, assim, o Caso Aunós nos desdobramentos que interfeririam nas relações Brasil/Espanha.

Aunós, em um primeiro momento, foi consultado pelo próprio Martín Artajo sobre sua suposta participação nos acordos com a Argentina e a Alemanha em $1942 .{ }^{15}$ Como já foi referido, Aunós negou todo tipo de envolvimento na questão em pauta, mas, em definitivo, o problema estava posto, uma vez que a veracidade ou não do conteúdo do Livro Azul era uma discussão que apenas iniciava.

A grande imprensa do Rio de Janeiro ocupou-se largamente do Caso Aunós, que ia além de um problema diplomático pelas implicações que trazia, como pode ser evidenciado não só pelo conteúdo dos jornais, como também pelo teor da documentação diplomática.

Para fins de análise, neste trabalho organizou-se as matérias dos jornais privilegiando as que contêm um caráter opinativo, já que as mesmas permitem avaliar com mais objetividade a posição da imprensa sobre o Caso Aunós. Distribuiu-se essas matérias em eixos temáticos, com base nos enfoques mais recorrentes nos jornais. Os textos de caráter informativo foram usados apenas quando ajudam a reconstruir os diferentes momentos em exame.

15 Na correspondência de Martín Artajo para Aunós se lê: "No obstante y sin perjuicio del informe que agradeceré me envíe telegraficamente a su llegada a Río de Janeiro, le ruego me anticipe cualquiera consideración que estimara conveniente para responder alusiones de contacto V. E. con representación de Alemania en Buenos Aires, único extremo que interesa aclarar" (cf. FRIGALLO, op. cit., p. 62-63.) 
Quanto à correspondência diplomática, cuidou-se de examiná-la em consonância com os eixos temáticos criados a partir dos jornais, tendo em conta que as questões sobre o Caso Aunós em que o Itamaraty se deteve, na sua maior parte, coincidem com as destacadas pelos jornais, excluindo, como é natural, alguns desdobramentos conhecidos apenas no âmbito oficial.

Os eixos temáticos que se passará a examinar são os que constam nos subtítulos que seguem.

\section{Aunós e o nazi-fascismo}

Com publicação do Livro Azul, a expectativa no meio oficial, que era positiva quanto à posse de Aunós na embaixada espanhola no Rio de Janeiro, seria substituída por uma avalanche de opiniões contrárias. Foi nessa mesma direção que a imprensa carioca passou a opinar, acusando Aunós de nazi-fascista e alertando que teria ele, com as negociações dos Acordos, contribuído para armar a Argentina, que planejaria atacar o Brasil.

O Diário de Notícias, que sempre defendera durante a guerra a posição do Brasil junto aos Aliados, vinculava estritamente Aunós ao Reich alemão e também tratava de incriminar a Argentina. Assegurava que o embaixador, ao tentar facilitar o abastecimento das Forças Armadas argentinas com material bélico alemão através da Espanha, contribuíra para aumentar o risco de levar o continente à conflagração. Aunós seria como um "caixeiro viajante do Reich". ${ }^{16}$

Aprofundando a análise feita, na seqüência do mesmo texto, o Diário de Notícias defendia uma postura que era comum com a de outros jornais: as "atrevidas tradições falangistas" de Aunós constituíam "as mais negativas credenciais com que uma diplomacia possa se apresentar". E, para arrematar os argumentos contra o embaixador, acrescentava: "já nos achamos suficientemente assoberbados por problemas de ordem interna deixados pela ditadura para que importemos mais esse: um sabotador da democracia".

Para melhor compreender os comentários do Diário de Notícias, é preciso ter presente que nas eleições para a Presidência da República do Brasil, de dezembro de 1945, o mesmo defendeu a candidatura de Eduardo Gomes. Como esse foi derrotado pelo General Eurico Gaspar Dutra, ex-Ministro da Guerra de Getúlio Vargas e apoiado por ele nas eleições, o Diário de Notícias passou a considerar o novo presidente como um seguidor da orientação

16 Rio de Janeiro, 19 de fevereiro de 1946. 
política de Vargas. Logo, não chega a surpreender que afirme estarem os brasileiros naquele momento (fevereiro de 1946), "assoberbados por problemas de ordem interna deixados pela ditadura".

A crença na vinculação de Aunós com o nazi-fascismo também foi referida por $O$ Jornal, sempre preocupado em demonstrar sua ligação com a democracia, conforme orientação de seu proprietário, Assis Chateaubriand. Em 23 de fevereiro de 1946, O Jornal abriu espaço para um texto de Fernando Ortiz Echague, ${ }^{17}$ onde estavam citadas declarações do Chanceler João Neves da Fontoura, ${ }^{18}$ exaltando a conveniência de manter estreitas ligações com os EUA, postura também muito cara ao jornal devido à orientação que recebia. Na mesma intervenção do Chanceler, esse afirmava que colaborar com os EUA era uma forma "de impedir a repetição do nazi-fascismo".

De maneira muito semelhante se manifestou o Correio da Manhã, também ao comentar a coletiva de João Neves da Fontoura sob o título: "Necessidade de impedir a reprodução da era nazifascista". Desde 1940, o Correio da Manhã defendia a importância do Brasil estar junto aos Aliados, especialmente os EUA.

O Diário Carioca foi outro periódico que retomou a questão nazi-fascista, ao comentar declarações de Aunós feitas em Curaçao, após ser notificado das acusações que o envolviam. ${ }^{19}$ A posi-

"O episódio Aunós e o Livro Azul", p. 1.

18 Tal pronunciamento de Neves da Fontoura foi a primeira manifestação oficial pública sobre o Caso Aunós. Tratou-se de uma entrevista coletiva concedida a mais de cem jornalistas, onde, apesar de ser duro com Aunós e suas supostas ligações com o nazi-fascismo, apelou à imprensa "para que não complicasse a situação com fantasmas" (O Jornal, "Define o Itamaraty a posição do Brasil ante o Livro Azul", 20 de fevereiro de 1946, p. 1) O Jornal dava força ao Chanceler ao reconhecer "as armadilhas do assunto" (Caso Aunós, ibidem). É muito provável que Neves da Fontoura estivesse especialmente preocupado com as acusações que estavam sendo feitas à Argentina, como se verá a seguir, pois apesar dos antagonismos que muitas vezes pautavam as relações entre esse país e o Brasil, são conhecidas as atitudes conciliadoras buscadas quando tais antagonismos chegavam a um nível perigoso de virulência.

19 Sobre as declarações de Aunós, são esclarecedoras também as informações repassadas pelo Jornal do Comércio, que, inclusive, explicam como teria sido feito, segundo o Livro Azul, o contato entre Aunós e Otto Meynen, Encarregado de Negócios da Alemanha em Buenos Aires. Em 15 de fevereiro de 1946 o Jornal do Comércio publicou sob o título: "Esperam informações do Brasil", o seguinte texto: "o Livro Azul norte-americano afirma que Otto Meynen, comunicou a Berlim, em 1942, que Aunós estava resolvido a fazer tudo o que estivesse ao seu alcance para que a Argentina pudesse receber armas da Espanha e da Alemanha .... para certas necessidades e possibilidades [...]. Em agosto de 1942, Aunós disse a Meynen que foi assinado um acordo entre Espanha e Argentina para facilitar a esse país sul-americano com munições e pólvora cujo cumprimento só poderá ser efetuado com a ajuda da Alemanha". Sobre a reação de Aunós frente a tais acusações, escreveu Pimentel Brandão para o Ministério de Relações Exteriores: "[Aunós] desmente categoricamente a alegação do 
ção que assumiu o Diário Carioca é bastante curiosa, se tivermos em conta que, embora em 1946 defendesse a democracia, durante o Estado Novo apoiara Getúlio Vargas com a frágil justificativa de que o autoritarismo preservava a democracia. Na verdade, essa justificativa encobria as pretensões de José Eduardo de Macedo Soares, fundador do jornal, que esperava chegar a ser interventor no Rio de Janeiro.

O texto do Diário Carioca, assinado por Antônio Bento, já traz no título uma idéia sugestiva: "O Álibi do Embaixador Aunós". ${ }^{20} \mathrm{~A}$ clara intenção do autor, que o jornal respaldava dado o espaço que lhe oferecia, era altamente mobilizadora contra o embaixador espanhol. Afinal, aceitar no Brasil um representante estrangeiro, capaz de atuação tão ardilosa, constituía um sério perigo que devia ser evitado, como se depreende das palavras de Bento:

As declarações do Sr. Aunós provam que ele é espertíssimo e tem a preocupação de arranjar um "álibi" qualquer para justificar-se das atividades fascistas. Por isso, enquanto arranjava víveres e materiais estratégicos para o Eixo, manifestava de público suas simpatias pelas Nações Aliadas. Chegou mesmo a dar "ciência" às embaixadas norte-americana e britânica dos resultados de sua excursão a Buenos Aires. Talvez tenha sido essa preocupação de fazer um trabalho limpo ou de praticar um "crime perfeito" a causa da desgraça de don Eduardo. As chancelarias de Londres e Washington logo desconfiaram, pois sabiam muito bem que os espiões sempre empregam tais processos. Enfim. O Sr. Aunós tem o cuidado de preparar o terreno antes de agir. É um homem experiente o antigo ministro do general Franco...

O Jornal do Comércio igualmente relacionou a impossibilidade de Aunós assumir a embaixada depois de conhecer "certas ativi-

alemão com quem somente esteve quatro vezes durante cinco meses passados na Argentina: duas vezes em banquetes de protocolo, uma ao chegar, outra na partida, como fizera com todos os chefes de missão ali. Desafia que se apresente qualquer prova de simples negociação" (AHI, Madrid -Telegramas - Cópias-1946-31/5/6).

20 Rio de Janeiro, 22 d fevereiro de 1946. É interessante observar que a imprensa espanhola também apresentava "álibis" no caso para inocentar o Embaixador espanhol. Em 13 de fevereiro de 1946, o ABC de Madri, na página 11, sob o título "Hasta ahora todo es falso", argumenta o que segue: "Cuanto dice el documento [o Livro Azul] hasta ahora, es decir, lo que de él conocemos en relación con nuestra Patria, es totalmente falso. Se dice, entre otras cosas, que España iba facilitar armas, barcos, y puertos para que la Argentina implantara el régimen nazi y lo impusiera después a los países próximos. En una palabra: que parecía que iba servir de mediadora para esos menesteres. No. Rotundamente, no. En primer lugar, había una imposibilidad física de hacer ese traslado de armas porque los barcos, todos los barcos que salían de España para América eran registrados en Gibraltar, luego en Trinidad a la ida y retorno. Pero, en segundo término, había un imposibilidad moral." 
dades nazi-fascistas no Prata" que o envolviam em "uma ação subversiva". ${ }^{21}$ Como esse jornal se caracterizara durante a II Guerra por ter um declarada posição contra o Eixo, explica-se que defenda esse ponto de vista.

Se para o Diário de Notícias Aunós era um "caixeiro viajante o Reich", "sabotador da democracia"; se O Jornal endossava o pronunciamento de João Neves da Fontoura, quanto à necessidade de impedir nova era nazi-fascista; se o Diário Carioca considerava que Aunós buscava um álibi para justificar suas atividades nazifascistas; se o Jornal do Comércio acreditava que Aunós se envolvera com atividades nazi-fascistas no Prata, fica evidente que esses jornais, representantes da grande imprensa do Rio de Janeiro, tratariam de apoiar as medidas que fossem tomadas para impedir a vinda de Aunós para a embaixada espanhola.

Que o Caso Aunós era um tema polêmico, não havia a menor dúvida. Envolvia não só as relações Brasil/Espanha naquele momento, como também trazia à tona a velha discussão sobre as relações Brasil e Argentina.

\section{Aunós e o equilíbrio de poder entre Argentina e Brasil}

O Diário de Notícias tratou de alertar para o perigo que representaram as negociações de Aunós. Tal postura é bastante lógica, considerando que, desde há muito, o jornal apoiava a política dos EUA $^{22}$ muito hostil à Perón, já praticamente eleito como presidente da Argentina.

Em sucessivas edições, entre 13 e 15 de fevereiro de 1946, desenvolveu o jornal toda uma argumentação no sentido de demonstrar que o material bélico negociado por Aunós contribuiria para viabilizar represálias argentinas contra o Brasil. Com essa argumentação o jornal não escondia a intenção de atacar o peronismo. É preciso ter presente que, em 1942, quando Aunós esteve em Buenos Aires negociando com os argentinos, Perón já era um político muito influente em seu país, tanto que no ano seguinte, além

"Solução Airosa", 23 de fevereiro de 1946, p. 2.

2 É significativo o fato de que, em 1948, Orlando Dantas, diretor do jornal, tenha recebido de Dwight Eisenhower, então reitor da Universidade de Columbia, o Prêmio Maria Moors, pela sua atuação como jornalista. O Prêmio era uma das mais importantes distinções da área de comunicação no continente americano. 
de ter sido um dos organizadores do GOU 23 assumiu o Ministério da Guerra e o Departamento Nacional do Trabalho.

Nem bem conhecido o conteúdo do Livro Azul, o Diário de Notícias já encabeçava a edição de 13 de fevereiro de 1946 com a seguinte manchete, que ocupava toda a extensão da primeira página: "Ataque da Argentina ao Brasil com armas fornecidas pelo Eixo". No corpo do texto, o que se lê é que as armas não teriam chegado à Argentina somente porque a Alemanha derrotada "não dispôs mais de armamentos suficientes nem para si mesma". ${ }^{24}$

Ainda no dia 13 de fevereiro de 1946, com o título "O documento confirmou a reportagem", na página 1, o Diário de Notícias voltava a reiterar as intenções belicistas "do governo fascista da Argentina contra toda a América, especialmente o Brasil". Tal idéia era reafirmada, ainda, em outro texto da mesma página: "Aunós também participou na conspiração contra o Brasil".

Entre 14 e 15 de fevereiro de 1946 há uma série de comentários fazendo afirmações de que os integralistas brasileiros estariam implicados nos planos da invasão argentina. ${ }^{25}$

$\mathrm{O}$ agendamento em torno ao repúdio do Embaixador espanhol feito pela imprensa pressionava quanto à urgência de uma solução definitiva para o Caso Aunós.

No dia posterior ao conhecimento do Livro Azul, era expedido para Madri um telegrama urgente e confidencial do governo brasileiro, nos seguintes termos:

Aunós figura como implicado nas manobras nazistas na América do Sul. Estamos apurando informaç̃es do documento [o Livro Azul], mas parece que seria aconselhável para evitar não só explorações nos círculos políticos brasileiros, mas também a má interpretação

23 O Grupo de Oficiales Unidos (GOU) era uma associação secreta que congregava militares argentinos na sua maioria simpatizantes dos regimes nazi-fascistas. Teve grande influência na vida política da Argentina, especialmente no início da década de 1940.

24 Cumprindo também o objetivo de alcançar os peronistas com seus comentários, o Diário de Notícias assegurava, nesse mesmo texto, que o governo argentino mantinha medidas de aparente cunho democrático.

$25 \mathrm{O}$ ataque do Diário de Notícias aos integralistas sempre foi explícito, pois o jornal considerava que as propostas dos mesmos, além de serem contra os valores liberais, eram usadas por Getúlio Vargas para justificar a repressão política que exerceu durante o Estado Novo. A postura alarmista do Diário de Notícias é confirmada também pela estratégia de colocar algumas manchetes sensacionalistas sobre outros temas, como a que segue: "Exigida a ruptura das relações diplomáticas com a Argentina" (15 de fevereiro de 1946 em toda a extensão da primeira página). A manchete correspondia ao rompimento da Argentina com os EUA, o que é explicado apenas no corpo do texto, logo o leitor mais apressado podia tirar outras conclusões se não lesse a notícia por inteiro. 
que poderia ser dada ao caso no continente, que o novo embaixador espanhol não chegasse agora ao Rio de Janeiro e interrompesse a sua viagem em algum posto intermediário em que tocar o Cabo de Buena Esperanza.

O posicionamento do Itamaraty era ousado, pois Aunós, que recebera o agrément do governo brasileiro em 21 de janeiro de 1946, já se encontrava em viagem ao Rio de Janeiro para assumir seu posto, como foi referido antes.

Acompanhando a correspondência sobre o Caso Aunós no Arquivo Histórico do Itamaraty, constata-se que o afastamento do embaixador transformou-se em uma questão de alta prioridade. Logo após o telegrama de 13 de fevereiro de 1946, que se acaba de citar, o Itamaraty reforçou as considerações ali colocadas em outro telegrama confidencial e urgente: “... temos necessidade urgente saber se esse governo deu as providências precisas para evitar que o embaixador Aunós desembarque nessa capital. [...] isso é essencial para o governo brasileiro". ${ }^{26}$ Ficava por ser administrada a forma mais adequada de o governo alcançar seus objetivos em relação a Aunós, tentando evitar que fosse criado um sério problema diplomático com a Espanha. ${ }^{27}$

\section{Aunós e as questões diplomáticas de seu afastamento}

Como se pôde observar até aqui, a impossibilidade de Aunós vir a assumir a embaixada de seu país no Rio de Janeiro era um fato consumado, por razões oficiais e pela forma como a imprensa vinha tratando a questão.

A primeira sugestão do Itamaraty para que o governo espanhol impedisse avanços indesejáveis para o Caso, não foi acatada. Assim, em telegrama confidencial e urgente instruía o Embaixador brasileiro em Madri, Pimentel Brandão, para que insistisse na solução sugerida, ou seja: evitar a chegada de Aunós ao Rio de Janeiro. Nesse mesmo telegrama é indicado o rumo que seria dado à questão em pauta, se o governo espanhol não mudasse de opinião: "seremos obrigados a declarar Aunós persona não grata, pois a origem e publicidade da denúncia, bem como as conveniências inter-

AHI.-Madrid -Telegramas (1946-1949)-31/5/2. Madrid, 14 de fevereiro de 1946.

7 Nesse sentido, o Itamaraty insiste em vários momentos: cf. em AHI, Madrid - Telegramas (1946-1949)-31/5/2, os telegramas de 13 de fevereiro de 1946 e 16 de fevereiro de 1946; em AHI, Madrid -Telegramas - Cópias (1946)-31/5/6 os telegramas de 18 de fevereiro de 1946 e 20 de fevereiro de 1946. 
nas, desaconselham que Aunós aqui desembarque no caráter de embaixador da Espanha". 28

O fracasso das negociações de Pimentel Brandão já era evidente em 15 de fevereiro de 1946, como demonstra um longo telegrama que enviou nessa data ao Rio de Janeiro:

O ponto de vista do Ministro de Negócios Estrangeiros é o seguinte: manter seu Embaixador, pois tem a acusação formulada na conta de calúnia e não deseja retirar-lhe a confiança, dando assim a impressão a todo mundo de que o acredita culpado. Ao contrário, confia absolutamente na inocência de Aunós e mostra-se desejoso de que desembarque no Rio de Janeiro, onde com seu tato, competência, inteligência e habilidade, irá se defender, se for preciso, pois não transcende de sua pessoa. Neste ponto o Ministro dos Negócios Estrangeiros mostra-se irredutível..$^{29}$

No mesmo telegrama, Pimentel Brandão revelava que, apesar da posição manifestada pelo Ministro, acreditava que Aunós pediria demissão "para não comprometer mais a causa espanhola já tão mal parada". 30

O governo brasileiro, definindo posição a 18 de fevereiro de 1946, remeteu a Pimentel Brandão um telegrama em que informava ter o presidente Dutra declarado Aunós persona non grata. De nada

28 AHI - Madrid - Telegramas (1946-1949)-31/5/12 - Rio de Janeiro, 16 de fevereiro de 1946. Também no Congresso Nacional reunido para elaborar uma nova Constituição para o Brasil, a posse de Aunós na Embaixada da Espanha foi condenada, como se pode inferir do pronunciamento do deputado Domingos Neto de Velasco, do partido União Democrática Nacional (UDN) de São Paulo, embora o representante espanhol não tenha sido citado nominalmente. O deputado referido, depois de lembrar que desde 1934 alertava para o processo de fascistização do governo de Getúlio Vargas, o que lhe custara amargar em uma prisão, acrescentou: “... diante dos novos fatos, que culminam nas afirmações do Departamento de Estado norte-americano, quero novamente alertar a Nação contra os perigos que a ameaçam. Nossa pátria está transformada em campo de operação do fascismo internacional [...]. Franco despachou outro do falangismo que vem certamente retornar a sua posição de articulador do fascismo, de que o acusa o Departamento de Estado". Ao final da alocução de Velasco, está registrada nos Anais do Congresso a manifestação de alguns elementos do plenário: "Muito bem, muito bem, palmas" (cf. Anais da Assembléia Constituinte, Rio de Janeiro: Imprensa Nacional, vol. I, 8 Sessão, 15 de fevereiro de 1946, p. 287-288).

29 AHI - Madrid - Telegramas - Cópias - 1946-31/5/6.

30 É importante ter presente que além das acusações enfrentadas pela Espanha em decorrência do Livro Azul, havia os embargos diplomáticos impostos ao governo de Franco por diversos países. Por outro lado, justamente em fevereiro de 1946, a execução de dez republicanos espanhóis e o julgamento de trinta e cinco outros, acusados todos de tentar reorganizar o Partido Socialista na Espanha, resultaram em sérias represálias. O governo francês, por exemplo, chegou a cogitar a intervenção da ONU contra o caudilho espanhol. 
valeram os argumentos de Pimentel Brandão que, dias antes, tentara minimizar as acusações que recebera o embaixador espanhol:

Aunós, como todos os políticos espanhóis, conheceu as realidades da força alemã na intenção de implantar uma ordem nova; teve que transigir com eles, porque não era possível fazer de outro modo e como era conveniente para seu país, que não queria, nem podia bater-se, por achar-se esgotado pela revolução. Mas, dos políticos espanhóis, Aunós era o menos inclinado a qualquer tendência germânica. ${ }^{31}$

Um mês depois (15 de março de 1946), Pimentel Brandão voltava ao mesmo tema em outro telegrama confidencial:

O subsecretário permanente dos Negócios Estrangeiros [da Espanha] pensa que Aunós teria conversado com os alemães como conversaria com os ingleses e norte-americanos, no próprio interesse de sua missão [de 1942, em Buenos Aires], mas nega a existência de um tratado. [...]. Se esse é o ponto de vista deste governo, nós não poderemos, creio eu, ser mais papistas do que o Papa. Aceitação de Aunós não nos compromete. É inatacável sob o ponto de vista do direito e da práticas internacionais. Poderíamos quiçá, agora declarar Aunós "persona non grata" e não entramos no mérito das acusações, mas sim das conveniências políticas do momento [...]. Mas se vamos começar a abrir devassa contra tudo e todos, baseados em documentos alemães, não é possível prever onde há de parar o mundo, rolando em confusão. ${ }^{32}$

Contudo, para Dutra era altamente oportuno assumir o papel de arauto da democracia, depois de sua atuação durante o Estado Novo e após ter sido apoiado por Getúlio Vargas na campanha presidencial. Logo, tornava-se conveniente sacrificar Aunós, declarando o mesmo "persona non grata", tanto por seus vínculos com a Alemanha no passado, quanto pelas "conveniências políticas do momento", entendidas como uma referência à ditadura de Franco na Espanha. ${ }^{33}$ Bruno Ayllón Pino ${ }^{34}$ chama também a aten-

31 AHI - Telegramas - Cópias -1946. Em 15 de janeiro de 1946, quando o Livro Azul ainda não era conhecido, Pimentel Brandão informara ao Rio de Janeiro que "durante a II Guerra Mundial as simpatias de Aunós pela causa aliada foram manifestas". Aunós, por sua vez, como noticiaram todos os jornais ao saber das acusações que lhe eram atribuídas, argumentou que se fosse a favor dos alemães, teria ficado na Bélgica, onde servia como embaixador, quando as tropas nazistas invadiram esse país (1940). No entanto, como outros que apoiavam os Aliados, retirou-se.

32 AHI - Telegramas - Cópias-1946.

33 Oficializado o afastamento de Aunós, esse, desde Curaçao, seguiu para Buenos Aires, onde desembarcou. Ainda em Curaçao, o embaixador teve de enfrentar outra dificuldade bastante curiosa. O navio Cabo de Buena Esperanza, em que viajava, foi detido pelas autoridades locais "enquanto se discutia o pagamento dos prejuízos causados por outro navio espanhol, o Cabo Hornes, numa ponte à entrada do porto, 
ção de que Dutra encontrava-se "completamente flexível às exigências dos Estados Unidos no referente à necessidade de castigar aqueles países simpatizantes dos regimes nazista e fascistas", na expectativa de consolidar as ligações de toda a ordem com o país do norte, de liderança incontestável no pós-guerra.

O Jornal do Comércio, em 23 de fevereiro de 1946, colocava o Caso Aunós na sua real dimensão: "A verdade é que, em vésperas de entrar no exercício de funções diplomáticas de tão grande destaque, estaria esse funcionário [Aunós] impossibilitado de exercê-las [...], por mais cabal que venha a ser, um dia, a sua defesa". Faltava, segundo o mesmo jornal, algo fundamental: a confiança junto ao governo em que estava acreditado. ${ }^{35}$ A posição do Jornal do Comércio pesava muito, mesmo considerando que esse não acompanhou as modernas formas de edição de seus concorrentes, com que perdeu muitos leitores. Contudo, entre empresários e homens de negócio, importantes formadores de opinião, era ainda muito lido.

O Jornal mais radical, quase raivoso, em texto assinado por Antônio Bento, que coincidia com a aversão de Chateaubriand aos regimes não democráticos, foi colocando um fim definitivo sobre o Caso Aunós:

Será melhor que não desembarque e que não arranje um visto no seu passaporte. Só assim sucederá ao embaixador do Caudilho o que, durante os anos críticos da guerra, acontecia aos judeus que, a bordo deste mesmíssimo "Cabo de Buena Esperanza" vagavam em desespero através do Atlântico, não encontrando em nenhum país uma autoridade que lhe fizesse a caridade de visar os passaportes. Agora, os escorraçados são os embaixadores falangistas e salazaristas. ${ }^{36}$

Qualquer recuo no Caso Aunós parecia inviável, mesmo considerando um argumento significativo exposto pelo do Jornal do Comércio: era impossível desprestigiar o embaixador espanhol "sem ofensa ao poder soberano que representa". ${ }^{37}$ Contudo, chama

danos esses avaliados em um milhão de florins" (cf. Jornal do Brasil, 21 de fevereiro de 1946, p. 9). Esse problema, contudo, seria superado porque, segundo O Jornal (21 de fevereiro de 1946), "Chegou a tempo soma que garantiu o pagamento dos danos causados",

34 As relações Brasil-Espanha na perspectiva da política externa brasileira (1945-2005). São Paulo: Emblema, 2006, p. 126.

35 "Solução Airosa", p. 2.

36 "O 'álibi' do Embaixador Aunós", 22 de fevereiro de 1946, p. 6.

37 "Solução Airosa", 23 de fevereiro de 1946, p. 2. O Correio da Manhã, em 27 de fevereiro de 1946, manifestou-se no mesmo sentido ao referir-se à ligação entre o embaixador espanhol e o Estado que esse servia: "Nunca se viu ou raramente se terá visto nos anais diplomáticos, que um embaixador do qual por sua categoria especial re- 
a atenção que não tenha havido, por parte da Espanha, uma reação à altura do acontecido, que transcendeu a área restrita do meio oficial diplomático para alcançar a discussão em ampla escala através da imprensa.

Alguns jornais se ocuparam do Caso Aunós, mesmo depois de o embaixador ter renunciado formalmente ao posto do Brasil, em 20 de fevereiro de 1946, alegando que assim poderia refutar as acusações que sofrera com mais liberdade.

O Jornal do Comércio foi um dos que insistia em examinar o Caso Aunós. A 23 de fevereiro de 1946, opinava que "se impunha ao próprio governo" afastar Aunós, uma vez que, "o havia acreditado de sua inteira confiança". Concluiu o jornal, no entanto, que o embaixador espanhol ao pedir demissão estaria, na verdade, cumprindo uma decisão governamental. 38 O Jornal, de 23 de fevereiro de 1946, através da publicação de um texto de Alfonso Mauri, tinha uma boa explicação para essa atitude: "o número de diplomatas estrangeiros em Madri já é muito escasso para que o governo espanhol tome qualquer medida enérgica [contra qualquer país]". 39

Para arrematar esses últimos comentários sobre o afastamento de Aunós, é fundamental conhecer a opinião do Correio da Manhã, mesmo tendo presente que essa era muito peculiar, dada à postura oposicionista do jornal em relação ao governo Dutra. ${ }^{40}$ Essa opinião, por outro lado, conduzia à nova discussão sobre a reação oficial espanhola ante os problemas com o Brasil, a qual contém argumentos que parecem dar sentido não só à fundamentação do jornal em pauta, mas também a de outros já citados.

O Correio da Manhã iniciava admitindo que o Brasil, no Caso Aunós, dada a forma como conduzira a cassação do agrément "tomou para com a Espanha uma atitude chocante". ${ }^{41}$ Tal atitude justificaria um protesto violento do governo espanhol, que não ocorrera.

presenta não somente a nação, mas também pessoalmente o Chefe de Estado, tivesse fechadas com dureza, quando já para elas caminhava, as portas que se lhe haviam aberto" ("Embaixadores", p. 1).

38 "Solução Airosa", p. 2.

39 "Possível Revide", p. 1.

40 Apesar de oposicionista, o Correio da Manhã não teria, no Caso Aunós, como condenar a atitude enérgica tomada pelo governo brasileiro. Restou-lhe, então, a opção de minimizar a importância política do substituto de Aunós, aceito pelo governo Dutra. A nomeação do novo Embaixador também seria explorada em outras dimensões, que, junto com a primeira situação exposta aqui, será examinada adiante.

41 "Embaixadores", em 27 de fevereiro de 1946, p. 1. 
A argumentação que vem a seguir tem a seguinte lógica: o Itamaraty ao vetar Aunós nunca pretendeu fazer uma represália "ao povo amigo da gloriosa Espanha". Com isso Franco e seu governo, que de forma inadequada acobertavam-se "com a Pátria para falar em nome dela [...], máximo anseio dos ditadores fascistas", deveriam sentir-se duplamente ofendidos com a represália a Aunós.

E, nesse ponto, questionava o jornal: "o que era natural? Que este [Franco] se irritasse e ameaçasse?”. A explicação vinha logo depois: “... Franco fez o que psicologicamente não poderia fazer. Dócil, tímido, resignado após o mínimo de protestos, nomeou logo outro embaixador no Brasil". E voltava a questionar o Correio da Manhã: "O que haverá por trás dessa singularidade?".

A resposta à última pergunta é todo um emaranhado de ironias ligadas ao novo Embaixador espanhol indicado para o Brasil, Conde de Casas Rojas. ${ }^{42}$ Para o Correio da Manhã, o substituto de Aunós era um elemento inexpressivo, "uma vaga figura na diplomacia espanhola, um velho aristocrata". Servira em Tanger e Constantinopla, logo, "especializou-se em baias e estreitos - podendo a Guanabara aguardar sem susto o confronto ante seus olhos". A ironia não acabava aí: não seria o chefe de missão "mais que um penacho ostensivo, sob o qual um elemento secundário é afinal a chave do enigma?". 43

Como se vai concluindo através do Correio da Manhã, era exatamente uma figura com o perfil de Casas Rojas que interessava ao governo de Franco manter no Brasil. Já que não conseguira colocar

42 É oportuno assinalar que o jornal madrileno $A B C$ ao publicar as decisões do Conselho de Ministros, na primeira página do dia 23 de fevereiro de 1946, chama a atenção que fora aceita a renúncia de Aunós do cargo de Embaixador no Rio de Janeiro, "en consideración a las razones de delicadeza que invoca a fin de que pueda, en plena libertad, refutar las infundadas imputaciones de que ha sido objeto en reciente documento diplomático”. Outro jornal, El Alcázar, apesar de incluir em sua página 7 uma sessão sob o título: "Nota Internacional", não faz nenhuma referência nem a Aunós, nem a Casas Rojas. Fica evidente que nem o tradicional ABC, nem o El Alcázar, afinadíssimo com o regime, estavam interessados em se deter sobre o Caso Aunós além do estritamente necessário. Isso explica a notícia sem grandes explicações do primeiro jornal e o silêncio do segundo.

43 Segundo Pimentel Brandão, a nova nomeação espanhola para a embaixada no Rio de Janeiro recaía sobre "um diplomata da mais alta distinção, a quem [o governo espanhol] ia confiar a direção política do Ministério." (AHI - Telegramas - Cópias 1946 - Madri, 20 de fevereiro de 1946). Considerando o cargo que estava previsto para Casa Rojas em Madri, é de se supor que, efetivamente, tratava-se de uma pessoa à altura do cargo no Brasil. Assim, as informações do embaixador brasileiro contrariam as opiniões desairosas sobre Casas Rojas emitidas pelo Correio da Manhã, que, implicitamente condenava a acomodação do governo brasileiro por não exigir uma pessoa mais qualificada para ocupar a embaixada espanhola. Cumpria, assim, o Correio da Manhã seu papel de jornal de oposição. 
Aunós, um eficiente e espontâneo colaborador, Casas Rojas poderia ser útil, pois, com seu pouco talento, agiria como um perfeito embaixador fantoche.

Três indagações referentes à nomeação de Casas Rojas finalizam o texto do Correio da Manhã: "Que será? Quem será? Por que será?". Essas indagações são altamente definidoras da intenção do jornal de desqualificar o novo Embaixador espanhol.

\section{Considerações finais}

Um primeiro aspecto que chama a atenção em fevereiro de 1946, quando o Caso Aunós envolve mais diretamente o Brasil devido à sua nomeação para o Rio de Janeiro, é que o foco da polêmica então criada está sob questões muito mais relacionadas com a Segunda Guerra Mundial, que acabara com a rendição alemã em maio de 1945 e a japonesa, em agosto do mesmo ano, do que com a Guerra Fria que dava seus passos iniciais.

Quando o governo brasileiro rejeita Aunós, como se examinou, a alegação era de que ele estivera relacionado com os fascistas, e é nesse sentido que o Caso Aunós está centrado muito mais no embate ideológico que marcou a Segunda Guerra (democracia $x$ fascismo) e não naquele que tipificaria a Guerra Fria (democracia $x$ comunismo).

Por outro lado, a preocupação evidenciada nos discursos contra a nomeação de Aunós é de que a democracia brasileira, a grande bandeira do governo Dutra, deveria ser resguardada, longe de influências perigosas, como a que representava o Embaixador espanhol devido às acusações que pesavam contra ele.

É oportuno ter presente que, em fevereiro de 1946, o fim do Estado Novo (29 de outubro de 1945) não completara nem quatro meses, e a acusação de que esse regime guardava semelhanças com o fascismo era uma questão muito presente. Tal situação tornava-se incômoda para Dutra, já que tivera uma atuação marcante no Estado Novo como Ministro da Guerra de Getúlio Vargas, além de ser considerado por muitos como simpatizante do fascismo. Contrariando seu passado político, Dutra se esforçava para identificar cada vez mais o governo que encabeçava com a democracia, visando, no contexto da Guerra Fria, um lugar destacado para o Brasil entre os países democráticos.

As circunstâncias políticas afastavam estrategicamente Aunós do Brasil, mesmo tratando-se de uma figura de grande projeção no 
seu país, até mesmo mais qualificada para o cargo do que seu substituto Casas Rojas.

O interesse com que os grandes jornais do centro do país acompanharam todos os desdobramentos do Caso Aunós, sem sombra de dúvida, foi um dos fatores que mais impulsionou para seu conhecido final. A aversão ao fascismo, a regimes autoritários, era, naquele momento, a marca de todos os jornais.

$\mathrm{O}$ risco que representaria para o Brasil qualquer iniciativa que visasse armar a Argentina em 1942 - como resultado dos acordos negociados por Aunós - foi outro fator que definiu a posição da imprensa, especialmente do Diário de Notícias contra o representante espanhol.

No que se refere à imobilidade do governo espanhol ante a inusitada resolução brasileira de rejeitar um embaixador com agrément concedido e já a caminho do Rio de Janeiro, é importante levar em conta, particularmente, as considerações feitas por $O$ Jornal acerca das dificuldades de reconhecimento que enfrentava o governo de Franco. Tendo a França, os EUA e a Grã Bretanha, em $1^{\circ}$ de maio de 1946, condenado o regime de Franco em nota comum, é certo que, mesmo antes de março, a resistência ao franquismo já sinalizava o rechaço. Esse seria consolidado com a resolução da Assembléia Geral da ONU, em dezembro de 1946, que recomendava aos seus Estados-membros retirar os seus respectivos embaixadores da Espanha.

Com tantos embates, por que iria o governo de Franco envolver-se com novos problemas que, com alguma habilidade, poderiam ser resolvidos? Assim, o Caso Aunós foi solucionado, como se viu, com a nomeação de um substituto que, não deixaria de ser útil, como analisou detidamente o Correio da Manhã na matéria "Embaixadores" de 27 de fevereiro de 1946. Sacrificava-se Aunós, que prometia provar sua inocência com melhores condições, por já estar afastado do cargo no Brasil. Ao mesmo tempo, alguns jornais espanhóis, como o $A B C$, seguiam defendendo Aunós sem grande alarde, enquanto outros, como El Alcázar, optavam por uma estratégia diferente: não chamar a atenção sobre um tema que podia implicar em constrangimentos para o regime de Franco ao qual estava estreitamente vinculado. É fácil perceber que havia uma orientação superior ditando as normas que deveriam ser seguidas nas editorias dos jornais, como não poderia deixar de ser nas circunstâncias da Espanha de então.

No que se refere à documentação diplomática examinada, ficou patente que o governo brasileiro não mediu esforços para afastar Aunós, propósito em parte justificado devido à maneira 
como a questão foi alardeada na imprensa. Pode ser argumentado, ainda, que formalizando a rejeição ao embaixador espanhol, o governo Dutra somava pontos a favor da democracia, da qual se ufanava ser defensor. É significativo ter presente que o discurso da imprensa, como se teve oportunidade de constatar, ajudou a construir a idéia de que a democracia brasileira estaria ultrajada, caso fosse confirmada a presença de um ex-aliado fascista na embaixada espanhola.

É também oportuno considerar que, mesmo aceitando a possibilidade de não ter sido posto em prática o acordo triangular Argentina, Espanha, Alemanha, tudo leva a crer que, pelo menos, houve negociações nesse sentido entre os três países. Tal entendimento não se anula com a informação transmitida a Martin Artajo pelo Departamento de Política Econômica da Espanha de que nada confirmava uma ação combinada hispano-germano-argentina.

Por outro lado, igualmente não neutraliza a possibilidade do citado entendimento a alegação feita por Aunós de que não teria se retirado da Bélgica ocupada pelas tropas de Hitler, caso mantivesse algum tipo de identidade com os nazistas. As condições européias em 1940 (ano da invasão à Bélgica) eram outras, ditadas pelo andamento da guerra, na qual Franco nunca assumiu abertamente uma adesão à Alemanha nazista. Com essa situação presente, cabe questionar: como se justificaria então a permanência de Aunós?

Quanto às ponderações feitas por Pimentel Brandão para amenizar as acusações que recebia Aunós, temos que reconhecer que são bastante inconsistentes, na medida em que só afirmam existirem eventuais simpatias de Aunós em relação aos Aliados durante a guerra, mas não fundamenta tal afirmação, como fica evidenciado na documentação apresentada (telegrama de 15 de janeiro de 1946). O argumento utilizado por ele um mês depois, em telegrama expedido para o Brasil, é igualmente vago. Nele considera que os documentos alemães não eram confiáveis para formalizar qualquer culpa de Aunós. Sem maior justificativa, em uma linguagem de efeito muito mais retórico afirma: "baseados em documentos alemães, não é possível prever onde há de parar o mundo, rolando em confusão".

Ao contrário do exposto até aqui, as evidências relativas ao envolvimento de Aunós com os alemães com vistas ao comércio de armas parecem bastante convincentes. Além do depoimento feito ao Departamento de Estado por de Dietrich Niebuhr, Agregado Naval da Alemanha, que confirma encontros mantidos com Au- 
nós, duas outras situações, pelo menos, comprometem o Embaixador Espanhol.

A primeira delas refere-se a ter sido hóspede do Conde de Guadalhorse na Argentina, onde desembarcou em 11 de março de 1946, para aguardar o retorno a Espanha, depois dos problemas que teve com o governo brasileiro. ${ }^{44}$ As vinculações, tanto de Aunós, como de seu hospedeiro Guadalhorse com a ditadura de Primo de Rivera, no mínimo ajudam a traçar o perfil do primeiro como de um homem desde há muito ligado a regimes de cunho direitista e autoritário.

A outra situação que interessa sublinhar procede de informação recolhida de dois jornais: o Jornal do Comércio, do Rio de Janeiro, de 15 de fevereiro de 1946 (p. 1) e La Prensa, de Buenos Aires, em $14 \mathrm{~d}$ fevereiro de 1946 (p. 7). Ambos os jornais afirmam que em outubro de 1942, quando Aunós retornava de navio para Espanha, após as negociações com os argentinos, por ocasião da escala feita no Rio de Janeiro, foi oferecido um banquete em sua homenagem. Osvaldo Aranha, então Ministro das Relações Exteriores do Brasil, recusou-se a participar do banquete, pois alegava possuir informações sobre o envolvimento de Aunós no comércio de armas entre Argentina, Espanha e Alemanha.

Apesar de persistirem dúvidas sobre uma versão definitiva para o Caso Aunós, no presente trabalho procuramos avançar no sentido de apresentar uma documentação pertinente que sugere algumas linhas de pesquisa interessantes para o estudo das relações internacionais, usando como fonte não só a documentação diplomática, como também a imprensa.

44 Gualdalhorse estava exilado na Argentina devido a seu envolvimento no Diretório Civil da ditadura do General Primo de Rivera. O próprio Aunós atuou no governo de Primo de Rivera em mais de um cargo no Ministério do Trabalho, o que também o obrigou a recorrer ao exílio (na França), após a queda daquele governo. 